\title{
Developing Emotional Intelligence In MBA Students: A Case Study Of One Program's Success
}

Fredricka F. Joyner, Indiana University East, USA

Derek T.Y. Mann, Performance Psychology Group, LLC, USA

\begin{abstract}
Over the past two decades an escalating interest in the construct of emotional intelligence (EI) has made its way into the popular press, professional press, and peer reviewed journals. Not surprisingly, an interest in EI is also gaining ground in academic settings (Parker, Duffy, Wood, Bond \& Hogan, 2002; Parker, Hogan, Eastabrook, Oke \& Wood, 2006; Parker, Saklofske, Wood \& Eastabrook, 2005). Several major longitudinal studies have laid a sound theoretical foundation supporting the development of EI competencies as a component of the MBA curriculum (Boyatzis, Stubbs \& Taylor, 2002; Boyatzis \& Saatcioglu, 2008). This paper will describe why and how one MBA program took theory to practice and piloted the integration of content designed to develop competencies related to emotional intelligence into its curriculum. It will also review the results of an applied multi-year study that measured the results of the curriculum pilot. The study was conducted using one of the most widely used instruments for measuring emotional intelligence, the Bar-On Emotional Quotient Inventory (Bar-On, 1997), to identify significant changes between the beginning and the end of the program in the aggregate measures of emotional intelligence competencies.
\end{abstract}

Keywords: Emotional Intelligence; MBA; EQ-I; Myers Briggs; Predictive Index; Integrative Thinking; Employee Engagement; Curriculum Design

\section{INTRODUCTION}

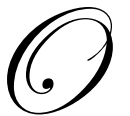

ver the past several years, the world into which MBAs graduate has undergone a fundamental transformation, resulting in what is being described by some as the "new normal." A recent study (Harris, 2011) identified three leadership challenges of the "new normal" - managing complex and rapid change, making decisions amid a climate of uncertainty, and standing out in a hyper-competitive marketplace. To thrive in the new normal, individuals must, among other things, think differently, lead differently, and have the ability to create engaging work environments for others.

This case study tells the story of how one MBA program piloted the integration of emotional intelligence (EI) content into its curriculum in order to better prepare its graduates to add value to their organizations and experience personal success working in the new normal. The case study also discusses the results of a multi-year study that measured the results of the pilot program. The study was conducted using one of the most widely used instruments for measuring emotional intelligence, the Bar-On Emotional Quotient Inventory (EQ-i) (Bar-On, 1997), to identify significant changes between the beginning and the end of the program in the aggregate measures of emotional intelligence competencies.

\section{WHO WE ARE}

This MBA has been offered by the regional campus of a major university in the Midwest since 2001. It is a 45 credit, general management program typically completed in 33 months. It is cohort-driven with approximately 
25 students in each cohort. While delivered on-site, the program is technology-enhanced. The program is career integrated, and, while most students are at their first or second career milestone, work experience varies from $1-33$ years at the point of admission. Students in the program are diverse representing 15 communities of residence, 45 employers, and 65 undergraduate institutions. Due to the mix of regional employers, a significant percentage of students are international. Approximately ten percent of the students hold a previous Master's degree.

\section{OUR THEORETICAL FOUNDATION AND CONTEXT}

In order to understand the context of this case study, let's begin with a whistle-stop tour that includes brief discussions of both theoretical underpinnings and the relevance of EI given the current rethinking of the MBA.

\section{Overview of Emotional Intelligence}

The construct of emotional intelligence was first defined by Salovey and Mayer (1990) as "the ability to monitor one's own and others' feelings and emotions, to discriminate among them and to use this information to guide one's thinking and action" (p. 189). Salovey and Mayer's original definition brought together the constructs of emotions and intelligence by viewing emotions as useful sources of information that help individuals make sense of their social environment. Mayer and Salovey originally conceptualized emotional intelligence as a group of related mental abilities that includes social, personal, and practical intelligences. They labeled these intellectual capacities as "hot cognitions" because they operate and deal with matters of personal, emotional importance to the individual (Mayer, Salovey, \& Caruso, 2004).

Goleman (1995) and Bar-On (1997) later broadened the notion of emotional intelligence to include an array of skills and traits that help people adapt to all aspects of life. Goleman defines emotional intelligence as the capacity to recognize our own feelings and those of others, to motivate ourselves, and to skillfully manage emotions in ourselves and in our relationships. Whereas, Bar-On (1997) defined emotional intelligence as an array of noncognitive skills and abilities that determines how effectively we understand and express ourselves, understand others and relate to them, and cope with daily demands. Although both of these definitions included emotion-related qualities such as emotional self-awareness, social awareness, and emotional understanding, many additional qualities such as reality testing, assertiveness, social responsibility, motivation, and independence are added within the Bar-on (EQ-i) framework.

\section{Emotional Intelligence and the MBA}

Many business schools are rethinking the curriculum of their MBA programs. This trend is due in large part to the current business and economic environment and the resulting increase in attention and criticism directed towards MBA programs. Ethical breaches of the last two decades followed by the severe weakening of the global financial system have left stakeholders from diverse arenas wondering about the appropriateness of traditional approaches to the educational preparation of business decision makers. Many of these critics have begun to question the fundamental relevance of the MBA (Elmore, 2010).

Criticism is being directed at both what and how business schools teach. "We show students how to value a company, how to price an option, how to manage away risk through securitization. But we are largely silent on the limits of those models, the pattern of assumptions that underlie them, and, most important, what to do when those models stop working" (Martin, 2010). Traditionally business education has been presented in disciplinary silos with the emphasis on analysis rather than on synthesis. "We teach them to focus with increasing blinders until they have pinpoint recognition, but that limits what they can see on the periphery" (Epstein, 2010). A major longitudinal study found that it is possible to develop cognitive and emotional competencies, but not through a typical MBA curriculum (Boyatzis, Stubbs \& Taylor, 2002). Recognizing these limitations, some of the new approaches being integrated into the MBA curriculum include activities aimed at preparing students to: collaborate effectively across disciplines; adapt to change; work with flexibility; and think critically. As MBA programs are redesigned, priority is placed on more fully linking content to context and ensuring that opportunities for decision making are integrated throughout (Epstein, 2010). 
The employer perspective is also critical to understanding the shortcomings of traditional approaches to preparing MBA students to function effectively in the current and future business environment. Hillmer and Kocabasoglu (2008) conducted an in-depth investigation to better understand employer desires and expectations for MBA programs. Surprisingly, the results indicated that the traditional focus of MBA programs, "knowledge of fundamental business concepts," was ranked 12th out of 15 dimensions identified as important by business executives. Consequently, The authors identified that "the most significant shortcoming of the current [MBA] curriculum, given the results of the research, was in the courses that aided the development of interpersonal skills." (p. 61)

As business schools engage in rethinking their curriculum and their approaches to developing business decision makers (the what and the how), the competencies associated with EI are becoming an increasingly important part of the conversation. Specifically, there is a growing recognition that skills and abilities such as adaptability, flexibility, critical thinking, and interpersonal skills are essential to the success of both individual business leaders and entire organizations.

\section{WHY WE FOCUSED ON EMOTIONAL INTELLIGENCE}

As stated earlier, three critical behaviors linked to success in the "new normal" are: thinking differently, leading differently, and creating engaging work environments for others. Let's take a quick look at each of these behaviors and at the connections between these behaviors and emotion.

\section{Thinking Differently}

An awareness of the need for integrative thinking in business settings is growing out of the collective experiences of the last several years. "Integrative thinking" is defined as a holistic perspective that moves away from either/or decision making toward considering options, welcoming complexity, and relying less on narrowly defined disciplinary constructs. (Martin, 2010). This awareness is creating a fundamental shift away from the application of formulaic tools and models that are prescriptive in nature and don't adequately recognize the importance of contextual variables. Emerging integrative approaches are based on an appreciation of complex system connections, generative critical thinking and problem solving, unprecedented levels of collaboration across traditional boundaries, and, effective engagement of an increasingly diverse set of stakeholders. Furthermore, there is an emotional component at the core of this shift because integrative thinking engages ideas both intellectually and emotionally (Martin, 2007).

\section{Leading Differently}

Because of today's constantly changing organizational environment, leadership positions often require more than just task competencies or technical know-how (George, 2000). The EI construct has garnered recent interest for its potential utility in leadership assessment and development (George, 2000; Huy, 1999; Law, Wong, \& Song, 2004; Rubin, Munz, \& Bommer, 2005). Riggio, Murphy, and Pirzollo (2002) propose that effective leaders possess multiple forms of intelligence, which allow them to respond successfully to various situations. In particular, scholars have noted that emotional skills are essential for executive level leader performance (Carmeli, 2003) and become increasingly important (compared to IQ and technical skills) as individuals advance within their organizational hierarchies (Dulewicz \& Higgs, 2003; Goleman, Boyatzis, \& McKee, 2002).

\section{Creating Engaging Work Environments}

MBA graduates are entering a business environment dominated by a shrinking talent pool. It is predicted that in 15 years, there may be as much as a $25 \%$ increase in demand for $35-45 \mathrm{yr}$ old workers while there will be $15 \%$ fewer Americans in the $35-45 \mathrm{yr}$ old range (Fishman, 1998). By 2030 it is anticipated that there could be $20 \%$ more jobs than workers in the U.S. (Employment Policy Foundation, 2001). These fundamental, long-term demographic patterns dictate that the demand for talent will continue to increase, and the amount of available talent will continue to decrease. Because of this, attracting and retaining top talent has become a strategic imperative for organizations. 
Over the past decade, the ability to attract and retain top performers has been linked to the development of a high engagement organizational culture. There have been numerous studies published that quantify this connection and begin to clearly identify various attributes of a high engagement culture (Ahlrichs, 2003; Buckingham \& Coffman, 1999; Gallup Consulting, 2008 \& 2010; Next Generation Companies, n.d.). As might be expected, strong common themes cut across these studies. In addition to identifying the specific attributes of the culture, many of these studies have gone on to identify the local manager as the critical player in building a high engagement culture. Most important is the manager's ability to create a relationship-rich workplace. Many of the EI competencies are central to building a relationship-rich, high engagement organization culture.

Due to the connection to emotion discussed in this section, the development of EI competencies was identified as a key developmental leverage point for the MBA students.

\section{WHAT WE DID}

During the multi-year pilot (spanning 2007 - 2010), content related to the development of EI competencies was integrated into all three years of the MBA curriculum. The content was linked, with each new content input building on and extending the content previously introduced, thus creating a "content thread." The decision to take such a comprehensive approach - not restricting the content to one course but integrating it into all three years of the program - was based on a belief in the fundamental connection between these competencies and personal, career, and ultimately business success discussed in the previous section.

The EI awareness and training protocol that comprised this content thread included the following steps:

- $\quad$ Develop deeper self-awareness in order to more fully answer the question: Who am I?

- Take time to identify the challenges, opportunities, expectations, and demands of the current context in order to more fully answer the question: What are the most important components of my context?

- Identify development opportunities and leverage points based on the combination of self-knowledge and the demands of the current context in response to the question: How can I increase my effectiveness?

- $\quad$ Establish and implement a development plan.

\section{Instruments Used}

Input from three instruments provided foundational information for this content thread. These instruments were the Myers-Briggs Type Indicator ${ }^{\circledR}\left(\right.$ MBTI $\left.{ }^{\circledR}\right)$, the Predictive Index ${ }^{\circledR}(\mathrm{PI} \circledast)$, and the EQ-i. The MBTI ${ }^{\circledR}$ and the PI ${ }^{\circledR}$ provide an understanding of fundamental aspects of an individual's personality, helping answer the question Who am I? The EQ-i identifies opportunities for competency development and helps answer the question "How can I increase my effectiveness?"

First published in the early 1960s, the MBTI® is generally recognized as the most widely used personality assessment (Myers, McCaulley \& Quenk, 1998). It is a personality inventory that measures individual psychological preferences on four key scales or dichotomies. These scales provide information on how an individual perceives the world and makes decisions. The PI®, in wide-spread use since 1955, measures a set of fundamental motivational needs related to control, social interaction, pace, and risk (Harris, Tracy \& Fisher, 2010). Taken together, these two instruments provide an individual with insight into fundamental aspects of his/her personality that are believed to be relatively stable over time. They help to develop an understanding of self in relation to fundamental questions such as:

- Where do I get my energy?

- What information to I draw upon when making decisions?

- What is my preferred work pace?

- What is my comfort level with ambiguity and decision-making risk?

- What is my level of interest in making social connections with others?

- $\quad$ Am I more interested in keeping options open or gaining closure? 
- $\quad$ How important is it for me to exert influence over people and events?

- Am I more comfortable as an individual operator or as a member of a team?

These questions address preferences and motivational drives that provide a starting point for developing deeper self-awareness and a fuller response to the question Who am I?

The EQ-i will be discussed in more detail in a subsequent section.

\section{Development Process}

In order to work through the three questions - Who am I?, What are the important components of my context?, and How can I increase my effectiveness? - key content milestones were designed as follows:

\section{Milestone 1 - Orientation}

During the orientation to the MBA program, the focus on the development of EI competencies, and the supporting business case, was introduced and discussed. For many of the students, this was their first exposure to the concept of a link between the explicit focus on the development of EI competencies and career and business success. The students then completed the three key instruments included in the content thread: the MBTI®, the $\mathrm{PI}$, and the EQ-i.

\section{Milestone 2 - Who Am I? and What Are the Important Components of My Context?}

Early in the first semester, students attended a weekend intensive seminar entitled HR Tools for Personal Development that incorporated the MBTI ${ }^{\circledR}$ and the PI®. The focus of the intensive was on developing a deeper understanding of fundamental personality traits and preferences. It also afforded participants an opportunity to explore and identify challenges, opportunities, and priorities in both a personal and professional context.

Completion of a final deliverable provided students with an opportunity to begin synthesizing their learning as it relates to the connections between self-awareness and career success. The instructions for that deliverable were as follows:

After reviewing the $\mathrm{PI}{ }^{\circledR}$ and the MBTI® information, please discuss the following:

- $\quad$ Generally speaking, one to three ways in which the PI® and/or the MBTI ${ }^{\circ}$ might be useful in a business setting.

- One thing about your "profile" or "type" that could possibly serve you well in being successful in school and/or in a business setting.

- Ideas you have about how you can use this possible "strength" to your advantage.

- One thing about your "profile" or "type" that could possibly be a challenge for you in being successful in school and/or in a business setting.

- Ideas you have about strategies you could use so that the "challenge" doesn't get in the way of your success.

Milestone 3 - How Can I Increase My Effectiveness?

At approximately the halfway point in the program, the students participated in a second weekend intensive focused specifically on the competencies that comprise the EQ-i. While it built on the first weekend intensive's focus on self-awareness and personal development, the second intensive was designed to focus more fully on career and professional development priorities. A training manual entitled $E Q \& Y o u$ (Cannon, 1999) provided the format for the intensive. Based on the results of their EQ-i assessment, students created a professional development plan and participated in a one-on-one coaching session with the course instructor. The assignment was as follows: 


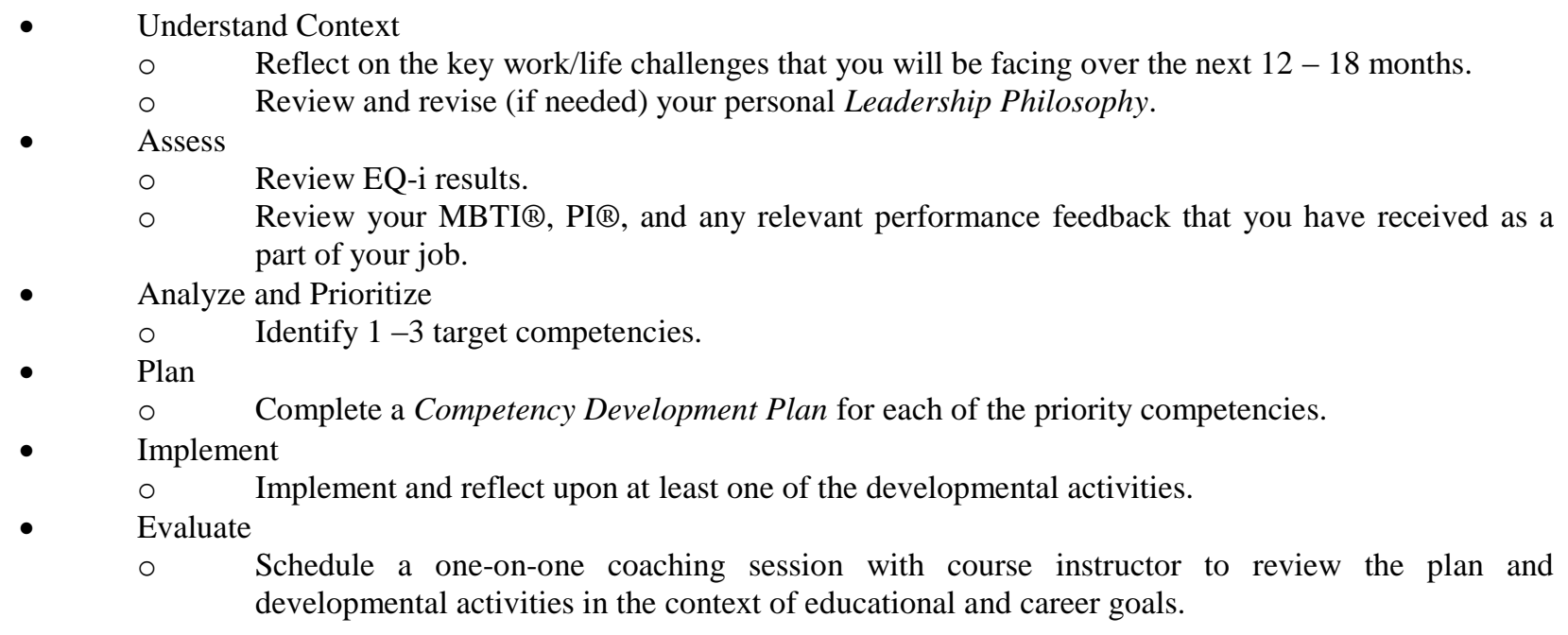

Milestone 4 - Self-analysis of Pre- and Post-EQ-i Scores

In the final semester of the program, as a part of a Leadership and Ethics course, students again took the EQ-i and completed an in-depth written analysis of their pre- and post-program scores. They were asked to comment on/address the following:

- $\quad$ Discuss the context of the last $2-3$ years - major changes, experiences, areas of focus, etc.

- Compare the results of the two assessments. Graphs and statistical analysis can be used here. Identify changes at the overall, composite scale, and sub-scale levels.

- $\quad$ Provide a detailed discussion of any changes identified. What meaning do you make of the changes? Make connections to the development plan you created based on the first assessment, any work-related development activities, developmental work assignments, etc. I am looking for an in-depth discussion here.

- $\quad$ Discuss any meaningful connections to the key models and conceptual frameworks you have worked with during the program.

- $\quad$ Discuss implications of this assessment based on what is on your $1-3$ year horizon.

- $\quad$ Discuss anything else that you feel is relevant.

- $\quad$ Make the most of this developmental opportunity.

\section{HOW AND WHAT WE MEASURED}

A research study (ultimately including 55 students) was designed to measure the efficacy of integrating emotional intelligence training into the program. The study focused on the research question, can significant changes be seen between the beginning and the end of the program in the aggregate measures of emotional intelligence competencies?

\section{Research Methods} as follows:

Changes were measured by administering the EQ-i pre- and post-program. The data collection method was

- $\quad$ During orientation, prior to any content delivery, the purpose of the study was generally explained. Students were encouraged to be candid as they completed the instrumentation and were ensured of the confidentiality of their responses.

- $\quad$ Students completed the informed consent document and a demographic information sheet.

- $\quad$ Students completed the EQ-i online. 
- $\quad$ The individual reports were scored online and the results downloaded.

- $\quad$ In the final semester of the program, students once again completed the EQ-i online.

- $\quad$ The individual reports were scored online and the results downloaded.

- $\quad$ Both pre- and post-program results were loaded into a spreadsheet and merged with the demographic data and pre- and post-program GPAs.

- $\quad$ After the information was merged, participant names were replaced with a numbering system so specific results could not be linked back to a specific individual.

\section{Measurement Instrument - The EQ-i}

The EQ-i is a self-report measure and is generally described as a skills-based model of EI. The Bar-On model (1997) involves an array of personal, emotional, and social abilities and skills. The EQ-i is comprised of 125 relatively short statements, in which responses are provided on a 5-point Likert scale ranging from "Very Often True of Me or True of Me" to "Very Seldom True of Me or Not True of Me." The EQ-i raw scores are converted into standard scores based on a mean of 100 and a standard deviation of 15 (Bar-On, 1997). The total EQ score breaks down into 15 content scale scores, which are clustered into five composite scores. The composite scores are Intrapersonal, Interpersonal, Stress Management, Adaptability, and General Mood. The subscales are Emotional Self-Awareness, Assertiveness, Self-Regard, Self-Actualization, Independence, Empathy, Interpersonal Relationship, Social Responsibility, Stress Tolerance, Impulse Control, Problem Solving, Flexibility, Reality Testing, Optimism, and Happiness (see Table 1). A higher score on any individual composite or subscale (or the total EQ-i score) implies stronger EI skills and a more positive prediction for effective functioning in meeting demands and challenges. Conversely, a lower EQ-i score suggests poorer EI skills and a reduced ability to be effective in meeting demands and challenges (Bar-On, 1997).

The reliability of the EQ-i has been examined by a number of researchers (Matthews, Zeidner, \& Roberts, 2002; Newsome, Day, \& Cantano, 2000; Petrides \& Furnham, 2000), with a consensus that the instrument is reliable, consistent, and stable. Bar-On (1997) reported that the internal consistency reliability of the overall EQ-i was 0.76 and the test-retest reliability was 0.85 after one month and 0.75 after four months. Additionally, several research studies have been conducted using the EQ-i to determine its construct validity and have shown a meaningful pattern of convergent validity with measures of psychological well-being and alexithymia (Dawda \& Hart, 2000), as well as with other measures of emotional and social intelligence (Bar-On, 2004). The EQ-i has also shown adequate discriminant validity with measures of cognitive ability (Bar-On, 2004; Van Rooy, Viswesvaran, \& Pluta, 2005) and personality (Van Rooy \& Viswesvaran, 2004).

In regards to criterion validity, Slaski and Cartwright (2002) found that the EQ-i was significantly correlated with morale (0.55), stress $(0.41)$, general health $(0.50)$, and supervisor ratings of performance $(0.22)$ in their study of retail managers. In another study of UK managers, Slaski and Cartwright (2003) found that training in emotional intelligence resulted in increased EQ-i scores and improved health and well-being.

\section{WHAT RESULTED}

While the pilot program did not include a discreet control group, the EQ-i normative data base provided a valid and appropriate comparison group for the purposes of analyzing results. The EQ-i has been stratified and normed on a population consisting of nearly 4,000 participants from across North America, providing the normative sample that was used as a comparison group to identify meaningful change over time. In a comparison of preprogram EQ-i scores from the MBA students to that of the EQ-i normative sample (Table 2), the males in the sample scored significantly $(p<.05)$ lower than the norm on self-actualization and interpersonal relationships, with no notable differences evident between females and the EQ-i normative sample. However, when comparing the postprogram results of both males and females to the normative population, males scored significantly $(p<.05)$ higher than the normative population on assertiveness, adaptability, flexibility, and problem solving. Moreover, females scored significantly $(p<.05)$ higher than the normative population on assertiveness, stress tolerance, and flexibility. (Note: While gender differences are noted as a part of the analysis methodology, the drivers for these differences were not a part of the scope of this study.) 
To assess the efficacy of the training and awareness protocol outlined in the previous section, a repeatedmeasures ANOVA was conducted. The results indicate a significant improvement in emotional and social functioning as measured by improvement of all EQ-i competencies, except for the dimensions of independence, selfregard, and self-actualization (Table 3).

Lastly, to determine the impact that the EI training may have on academic performance, pre- and posttraining GPA was analyzed across gender using a 2 × 2 repeated-measures ANOVA with axes of gender (male, female) and time (pre, post). Results indicate a significant improvement in GPA across time $(F(1,52)=76.54, p=$ $.001)$. However, the gender-x-time interaction was not significant $(F(1,52)=.164, p=.688)$, suggesting that both males and females were equally impacted by the effects of the training protocol over time.

Table 1: Emotional Quotient Inventory (EQ-i) Scales and Measurement Characteristics

\begin{tabular}{|c|c|}
\hline EQ-i Scales & EI Skills Assessed by Each EQ-i Scale \\
\hline Intrapersonal & Self-awareness and self expression: \\
\hline Self-Regard & To accurately perceive, understand, and accept oneself \\
\hline Emotional Self-Awareness & To be aware of and understand one's emotions \\
\hline Assertiveness & To effectively and constructively express one's emotions and oneself \\
\hline Independence & To be self-reliant and free of emotional dependency on others \\
\hline Self-Actualization & To strive to achieve personal goals and actualize one's potential \\
\hline Interpersonal & Social awareness and Interpersonal relationship: \\
\hline Empathy & To be aware of and understand how others feel \\
\hline Social Responsibility & To identify with one's social group and cooperate with others \\
\hline Interpersonal Relationship & To establish mutually satisfying relationships and relate well with others \\
\hline Stress Management & Emotional management and regulation: \\
\hline Stress Tolerance & To effectively and constructively manage emotions \\
\hline Impulse Control & To effectively and constructively control emotions \\
\hline Adaptability & Change management: \\
\hline Reality-Testing & To objectively validate one's feelings and thinking with external reality \\
\hline Flexibility & To adapt and adjust one's feelings and thinking to new situations \\
\hline Problem-Solving & To effectively solve problems of a personal and interpersonal nature \\
\hline General Mood & Self-motivation: \\
\hline Optimism & To be positive and look at the brighter side of life \\
\hline Happiness & To feel content with oneself and life in general \\
\hline
\end{tabular}

The comparison of the pre- and post-training program results of the MBA students to the EQ-i normative data base suggest that, while there were some gender-related differences, participation in the EI awareness and training protocol had a positive influence on the development of key EI competencies. The results of the repeatedmeasure ANOVA suggest improvement in emotional and social functioning as measured by a significant increase in 
most of the competencies measured by the EQ-i. Finally, the analysis of pre- and post-program GPA suggests that the development of EI competencies has a positive impact on academic success.

Table 2: Gender Differences in EI Development

\begin{tabular}{|c|c|c|c|c|c|c|c|c|}
\hline \multirow[b]{3}{*}{ EQ-i Scales } & \multicolumn{4}{|c|}{ Pre-Test } & \multicolumn{4}{|c|}{ Post-Test } \\
\hline & \multicolumn{2}{|c|}{ Males } & \multicolumn{2}{|c|}{ Females } & \multicolumn{2}{|c|}{ Males } & \multicolumn{2}{|c|}{ Females } \\
\hline & Mean & SD & Mean & SD & Mean & SD & Mean & $\mathrm{SD}$ \\
\hline TOTAL EQ-i & 97.3 & 13.6 & 100.1 & 10.8 & 102.5 & 10.7 & 104.7 & 11.7 \\
\hline INTRApersonal & 97.4 & 13.3 & 102.7 & 11.9 & 102.6 & 11.3 & 105.3 & 12.9 \\
\hline Emotional Self Awareness & 97.9 & 14.7 & 98.8 & 13.5 & 102.7 & 12.7 & 105.9 & 13.4 \\
\hline Assertiveness & 98.5 & 14 & 103.7 & 12.3 & $104.7^{*}$ & 11.6 & $108.6^{*}$ & 11.4 \\
\hline Independence & 100.1 & 12.5 & 103.6 & 7.4 & 102.9 & 14.3 & 103.6 & 11.2 \\
\hline Self-Regard & 97.7 & 12.4 & 105.4 & 14.6 & 101.1 & 11.2 & 103.5 & 14.7 \\
\hline Self-Actualization & $96.3^{*}$ & 12.7 & 99.6 & 12.3 & 100 & 11.6 & 100.5 & 12.7 \\
\hline INTERpersonal & $97.4 *$ & 13 & 96.6 & 11.7 & 100.6 & 12.1 & 103.6 & 11.8 \\
\hline Empathy & 98.5 & 16.6 & 94.8 & 10.7 & 101.2 & 14.7 & 102.3 & 13.4 \\
\hline Social Responisbility & 100.2 & 13.6 & 99.4 & 7.2 & 102.7 & 12.4 & 103.2 & 10.1 \\
\hline Interpersonal Relationships & 96 & 12.7 & 96.9 & 16.1 & 99.2 & 13.1 & 103.4 & 13 \\
\hline ADAPTABILITY & 98.8 & 14.3 & 99.7 & 11.8 & $104.5^{*}$ & 11.2 & 104.8 & 10.8 \\
\hline Problem Solving & 99.3 & 11.5 & 96.7 & 6.4 & $104.3^{*}$ & 12.2 & 101.1 & 8 \\
\hline Reality Testing & 98.2 & 14.4 & 99.8 & 14.3 & 103.3 & 12.4 & 102.9 & 13.7 \\
\hline Flexibility & 99.8 & 16 & 102.8 & 14.1 & $103.5^{*}$ & 11.2 & $107.6^{*}$ & 11.3 \\
\hline STRESS MANAGEMENT & 98.4 & 14.4 & 99.8 & 10.1 & 102 & 12.1 & 104.6 & 11.4 \\
\hline Stress Tolerance & 97.9 & 15.6 & 101.7 & 7.2 & 100.9 & 13.4 & $105.4^{*}$ & 10 \\
\hline Impulse Control & 99.3 & 14.1 & 97.9 & 13.5 & 102.5 & 13.4 & 101.8 & 14.4 \\
\hline GENERAL MOOD & 97.6 & 14.4 & 99.6 & 13.6 & 101.2 & 11.2 & 101.9 & 14.9 \\
\hline Happiness & 98.7 & 15.6 & 99 & 15 & 101.2 & 12 & 102.4 & 16.2 \\
\hline Optimism & 97.5 & 12.9 & 101.5 & 12 & 101.8 & 11.9 & 102.1 & 12.7 \\
\hline
\end{tabular}

* Denotes significant difference from the population norm.

$\mathrm{N}=55$

\section{WHY WE THINK THIS IS IMPORTANT}

To understand why success in the development of key EI competencies is good news, let's revisit the three critical behaviors for success in the "new normal" discussed earlier.

\section{Thinking Differently}

In addition to the general recognition of an emotional component in integrative thinking processes discussed earlier in the paper, the capacity for integrative thinking is specifically linked to several of the EI competencies. The ability to craft new models for action, innovate, and manage the resulting change is central to the emerging integrative approaches described above, and closely related to the competencies that comprise the composite scale of Adaptability. An individual must be able to engage in personal and interpersonal problem solving (Problem-Solving), calibrate one's thought and feelings with external reality (Reality Testing), and, perhaps most importantly, be capable of adapting one's thoughts and feelings to new situations (Flexibility). 
Table 3: EI Subscale Development Over Time

\begin{tabular}{|c|c|c|c|c|c|c|}
\hline \multirow[b]{2}{*}{ EQ-i Scales } & \multicolumn{2}{|c|}{ Pre-Test } & \multicolumn{2}{|c|}{ Post-Test } & \multirow[b]{2}{*}{$\mathrm{F}$} & \multirow[b]{2}{*}{ Sig } \\
\hline & Mean & SD & Mean & $\mathrm{SD}$ & & \\
\hline TOTAL EQ-i & 97.9 & 13 & 103 & 10.9 & 15.3 & 0.001 \\
\hline INTRApersonal & 98.6 & 13.1 & 103.3 & 11.7 & 15.9 & 0.001 \\
\hline Emotional Self Awareness & 98.1 & 14.4 & 103.5 & 12.8 & 15.8 & 0.001 \\
\hline Assertiveness & 99.8 & 13.7 & 105.7 & 11.6 & 21.6 & 0.001 \\
\hline Independence & 101 & 11.5 & 103.1 & 13.5 & 2.4 & 0.129 \\
\hline Self-Regard & 99.5 & 13.2 & 101.7 & 12.1 & 2.9 & 0.091 \\
\hline Self-Actualization & 97.1 & 12.6 & 100 & 11.8 & 4.5 & 0.038 \\
\hline INTERpersonal & 97.2 & 12.6 & 101.4 & 12 & 12.5 & 0.001 \\
\hline Empathy & 97.6 & 15.4 & 101.5 & 14.3 & 5.6 & 0.021 \\
\hline Social Responisbility & 100 & 12.3 & 102.9 & 11.8 & 4 & 0.05 \\
\hline Interpersonal Relationships & 96.2 & 13.5 & 100.2 & 13.1 & 11.2 & 0.001 \\
\hline ADAPTABILITY & 99 & 13.6 & 104.6 & 11 & 16.9 & 0.001 \\
\hline Problem Solving & 98.7 & 10.5 & 103.5 & 11.4 & 12.3 & 0.001 \\
\hline Reality Testing & 98.5 & 14.3 & 103.2 & 12.6 & 11.01 & 0.001 \\
\hline Flexibility & 100.5 & 15.5 & 104.5 & 11.3 & 7.7 & 0.007 \\
\hline STRESS MANAGEMENT & 98.7 & 13.4 & 102.6 & 11.9 & 8.1 & 0.006 \\
\hline Stress Tolerance & 98.8 & 14.1 & 101.9 & 12.7 & 5.4 & 0.023 \\
\hline Impulse Control & 99 & 13.9 & 102.3 & 13.5 & 5.5 & 0.022 \\
\hline GENERAL MOOD & 98.1 & 14.1 & 101.4 & 12.1 & 7.6 & 0.007 \\
\hline Happiness & 98.8 & 15.3 & 101.4 & 13 & 3.9 & 0.051 \\
\hline Optimism & 98.5 & 12.7 & 101.9 & 12 & 9.5 & 0.003 \\
\hline
\end{tabular}

A complex, turbulent, and therefore increasingly ambiguous, environment provides the backdrop for the emergence of integrative thinking. In this environment, well-developed self-management competencies are critical to effective action. The ability to be aware of and understand one's emotions (Emotional Self Awareness), to constructively manage those emotions (Stress Tolerance), and to effectively control them when necessary (Impulse Control) is essential. These competencies allow an individual to navigate uncertain terrain while maintaining emotional balance and, with that, the potential to effectively engage others.

Deep collaboration is integral to integrative thinking. It involves working across traditional boundaries and in contexts with unprecedented levels of diversity. In addition to increasing the potential for the development of integrative approaches, diverse contexts also increase the magnitude of differences and the levels and types of conflict. The ability to work effectively in this context is linked to many of the EI competencies bundled in the Intra- and Inter- Personal scales. To be aware of and understand one's emotions (Emotional Self Awareness) is critical and must be balanced with being aware of and understanding how others feel (Empathy). Collaboration also involves the ability to both identify with one's own social group and cooperate with others (Social Responsibility). It also involves the ability to express and act on one's own needs in a way that does not violate the needs of others (Assertiveness). The development of these competencies supports the capability of effective participation in collaborative approaches.

Integrative thinking is fundamentally holistic, seeking to integrate many ways of seeing, knowing and understanding. It is a both/and approach that draws on the rational and the emotional, the analytical and the intuitive and that is open to embracing seemingly opposing ideas and approaches. It requires that an individual develop rational, analytical competencies as well as competencies related to emotional intelligence. As recognition that integrative thinking is a key component in the development of successful responses to the current business environment grows, so will the interest in strategies to develop emotional intelligence competencies in future business leaders. 


\section{Leading Differently}

In order to lead effectively in an increasingly complex, turbulent, and ambiguous environment, leaders must be confident in their ability to manage their own emotions (Stress Tolerance, Impulse Control) and the emotions of others (Empathy, Interpersonal Relationships). Bar-On (1997) proposes that individuals with higher levels of EI have the ability to handle stressful situations without losing control and are able to maintain a calm composure when relating to others even while experiencing intense emotions. Sosik and Megerian (1999) suggest that emotionally intelligent people feel more secure in their ability to control and influence life events and, as a result, are able to provide individual focus on others as well as intellectually stimulate and motivate followers.

\section{Creating an Engaging Work Environment}

As discussed earlier, one of the key components of creating an engaging work environment is building relationships and building effective relationships with others begins with self. Heightened self-awareness opens up possibilities for more active and effective self-management. In other words, developing the capacity to proactively make choices about how to respond in a given situation, rather than responding reactively in "default mode." The ability to make choices and modulate one's responses increases opportunities to engage others more fully. Being aware of and understanding one's emotions (Emotional Self-Awareness) is at the starting point. The competencies that comprise the Interpersonal scale are most closely tied to relationship building. Being aware of and understanding how other feel (Empathy) and being able to establish mutually satisfying relationships and relate well with others (Interpersonal Relationships) are critical to developing the capacity to create and sustain a relationshiprich environment.

One of the challenges to creating and sustaining a relationship-rich, high engagement organization culture is the pace and pressure of today's complex and turbulent work environment. Balancing results and relationships in this environment requires well-honed emotional management. One poorly managed emotional outburst can undermine months, and even years, of relationship building. The competencies most closely related to this ability are contained in the Stress Management scale. An individual must be able to effectively and constructively manage emotions (Stress Tolerance) and effectively and constructively control emotions (Impulse Control) to be successful at this balancing act.

The mood of the manager can have a strong influence on the emotional field of the work environment, in other words "how it feels to work around here." The ability to generate a generally positive emotional field can be particularly important when competing to attract and retain top talent. Competencies related to this ability are contained in the General Mood scale. Being positive and looking at the brighter side of life (Optimism) and feeling generally content with oneself and life in general (Happiness) support one's ability to generate a generally positive emotional field in the work environment.

\section{CONCLUSION AND IMPLICATIONS FOR FUTURE WORK}

Enhancing the capacity for thinking differently, leading differently, and creating an engaging work environment are just three examples of the many ways in which the development of EI competencies can be a significant asset to students as they graduate and enter challenging and turbulent work environments. Success in these settings requires managers to have both strong disciplinary and inter-disciplinary knowledge along with tools, models and frameworks for analysis and synthesis and well-honed and continuously-improving EI competencies. There is a growing recognition that these are complementary skill sets, yet the intentional development of EI competencies has been largely overlooked by MBA programs. This study makes the case for why the development of EI competencies is important and how this focus can be integrated into an MBA program.

While small, the study provides an example of a successful approach to the development of traditionally overlooked competencies that are of strategic importance in the current and future business environment. Given the demands of the external environment and the interest throughout academia in rethinking the MBA, the study is well timed and provides a foundation for further work. Larger studies, perhaps utilizing control groups, can be planned to further understand the importance of these competencies within the framework of the MBA and to fine-tune 
approaches to their development. Understanding how to integrate the development of these competencies into the MBA curriculum is critical to the future success of the MBA programs themselves, the future decision-makers who graduate from the programs, and, ultimately, to the organizations that they influence.

\section{Some Lessons Learned and Tangential Benefits}

- $\quad$ For many of the students, this represented their first experience with instrumentation and structured selfreflection. For some of these students the value was not immediately evident, others found it fascinating from the start.

- Many of the students, especially those coming out of more technical disciplines, did not intuitively value the content thread at the beginning of the program. Most came to see the value over time, especially when they had work experiences that highlighted the connection between EI competencies and work and career success.

- Some faculty resisted committing program hours to the content thread, feeling that it took valuable time away from the core disciplines traditionally associated with an MBA.

- Introducing the instrumentation at the beginning of the program offered excellent opportunities for interaction and team building among the students.

- Inviting other program faculty to participate in the intensives provided unique opportunities to build connection and understanding between the faculty and the students.

- $\quad$ Encouraging students to pull workplace performance feedback into the development planning process provided rich opportunities to make meaningful connection between workplace and program-based learning.

\section{AUTHOR INFORMATION}

Fredricka F. Joyner is an associate professor of business administration and organization behavior on faculty at Indiana University East. Her teaching, research, and service interests include leadership development, employee engagement, civic engagement, and the scholarship of teaching and learning. In addition, Dr. Joyner maintains an active consulting practice focused on partnering with individuals, organizations, and communities to unleash potential and achieve new levels of performance. E-mail: fjoyner@iue.edu

Derek T.Y. Mann, Ph.D., is a performance enhancement consultant and has spent several years investigating the impact of emotion on human performance with elite populations which has been published in several leading professional and academic publications and most recently he has co-authored the "Emotional Intelligence Skills Assessment." Given his expertise in this domain, Dr. Mann has also served as a contributing editor to several leading academic and professional journals. Dr. Mann has contributed to the growth and accessibility of emotional intelligence through assessment, training and development, and professional presentations throughout North America. E-mail: Derek.mann.ppg@gmail.com

\section{REFERENCES}

1. Ahlrichs, N. (2003). Manager of choice: Five competencies for cultivating top talent. Palo Alto, CA: Davies-Black Publishing.

2. $\quad$ Bar-On, R. (1997). The Emotional Quotient Inventory (EQ-i). Toronto, Canada: Multi-Health Systems, Inc.

3. Bar-On, R. (2004). The Bar-On Emotional Quotient Inventory (EQ-i): Rationale, description, and summary of psychometric properties. In Glenn Geher (Ed.), Measuring emotional intelligence: Common ground and controversy. Hauppauge, NY: Nova Science Publishers, 111-42.

4. Boyatzis, R.E., Stubbs, E.C., \& Taylor, S.N. (2002). Learning cognitive and emotional intelligence competencies through graduate management education. Academy of Management Learning and Education, $1(2), 150-162$.

5. Boyatzis, R.E., \& Saatcioglu, A. (2008). A 20-year view of trying to develop emotional, social, and cognitive intelligence competencies in graduate management education. Journal of Management Development, 27(1), $92-108$. 
6. Buckingham, M., \& Coffman, C. (1999). First break all the rules: What the world's greatest managers do differently. New York: Simon \& Schuster.

7. Cannon, K. (1999). EQ \& you: Creating your EI development plan. Minneapolis, MN.

8. Carmeli, A. (2003). The relationship between emotional intelligence and work attitudes, behavior and outcomes: An examination among senior managers. Journal of Managerial Psychology, 18(8), 788-813.

9. Dawda, D. \& Hart, S. (2000), Assessing emotional intelligence: Reliability and validity of the Bar-On E Emotional Quotient Inventory (EQ-i) in university students. Personality and Individual Differences, 28 (4), 797-812

10. Dulewicz, V. \& Higgs, M. (2003). Leadership at the top: The need for emotional intelligence in organizations. International Journal of Organizational Analysis. Special Issue: Emotional Intelligence and Organizational Behavior-II, 11(3), 193-210.

11. Elmore, B. (2010, Spring). Keeping the MBA relevant. Baylor Business Review, 28(2), 19-23. Retrieved August 18, 2010 from http://www.baylor.edu/bbr/index.php?id=70707

12. Employment Policy Foundation. (2001). Labor demand will outstrip supply. In Employment Forecast: Contemporary Issues in Employment and Workplace Policy (figure2). Retrieved from http://web.archive.org/web/20030405060947/http://epf.org/research/newsletters/2001/ef20011025.pdf

13. Epstein, J. (2010, May 5). The post-crisis MBA. Inside Higher Ed. Retrieved August 18, 2010 from http://insidehighered.com/layout/set/print/news/2010/05/05/mba

14. Fishman, C. (1998, July 31). The war for talent. Retrieved August 23, 2010, from http://www.fastcompany.com/magazine/16/mckinsey.html

15. Gallup Consulting. $(2008,2010)$. Employee engagement what's your engagement ratio?. Retrieved from http://www.gallup.com

16. George, J. M. (2000). Emotions and leadership: The role of emotional intelligence. Human Relations, 53, 1027-1055.

17. Goleman, D. (1995). Emotional Intelligence: Why It Can Matter More Than IQ. New York: Bantam Books.

18. Goleman, D., Boyatzis, R. \& McKee, A. (2002). Primal leadership: Realizing the power of emotional intelligence. Boston: Harvard Business School Press.

19. Harris, T. C., Tracy, A. J. \& Fisher, G. G. (2010). 2010 Predictive Index® technical overview. Wellesley Hills, MA: Praendex Incorporated.

20. Hillmer, S. \& Kocabasoglu, C. (2008). Using qualitative data to learn about customer needs: understanding employer desires when designing an MBA program. The Quality Management Journal, 15(2), 51-63. Retrieved from ABI/INFORM Global database.

21. Huy, Q. N. (1999). Emotional capability, emotional intelligence, and radical change. Academy of Management Review, 24, 325-345.

22. Law, K. S., Wong, C., \& Song, L. J. (2004). The construct and criterion validity of emotional intelligence and its potential utility for management studies. Journal of Applied Psychology, 89, 483-496.

23. Martin, R. (2007, June). How successful leaders think. Harvard Business Review, 85(6), 60-67. Retrieved from EBSCOhost database.

24. Martin, R. (2010, April 13). Fear, loathing, and the MBA. Businessweek.com, 4. Retrieved April 14, 2010, from http://www.businessweek.com/bschools/content/apr2010/bs20100412 325561.htm

25. Martin, R. (2007, November/December). Innovation from the top. The Conference Board Review, 44(6), 14-16.

26. Matthews, G., Zeidner, M., \& Roberts, R. (2002). Emotional Intelligence: Science and myth. Cambridge: MIT Press.

27. Mayer, J. D., Salovey, P., \& Caruso, D. R. (2004). Emotional intelligence: Theory, findings, and implications. Psychological Inquiry, 60, 197-215.

28. Myers, I.B., McCaulley, M.H., Quenk, N.L., \& Hammer, A.L. (1998). MBTI manual: A guide to the development and use of the Myers-Briggs type indicator ( $3^{\text {rd }} \mathrm{ed}$.). Mountain View, CA: Consulting Psychologist Press.

29. Newsome, S., Day, A.L., \& Catano, V.M. (2000). The incremental validity of emotional intelligence. Personality and Individual Differences, 29, 1005-1016.

30. Next generation companies. (n.d.). Retrieved from http://www.nextgenerationcompany.com 
31. Parker, J. D. A., Duffy, J., Wood, L. M., Bond, B. J., \& Hogan, M. J. (in press). Academic achievement and emotional intelligence: Predicting the successful transition from high school to university. Journal of FirstYear Experience and Students in Transition.

32. Parker, J. D. A., Hogan, M. J., Eastabrook, J. M., Oke, A., \& Wood, L. M. (2006). Emotional intelligence and student retention: Predicting the successful transition from high school to university. Personality and Individual Differences, 41, 1329-1336.

33. Parker, J. D. A., Saklofske, D. H., Wood, L. M., Eastabrook, J. M., \& Taylor, R. N. (2005). Stability and change in emotional intelligence: Exploring the transition to young adulthood. Journal of Individual Differences, 26, 100-106.

34. Petrides, K.V. \& Furnham, A. (2000). On the dimensional structure of emotional intelligence. Personality and Individual Differences, 29, 313-320.

35. Rigigio, R.E., Murphy, S.E., \& Pirzolo, F.J. (2002). Multiple intelligences and leadership. Mahwah, NJ: Lawrence Earlbaum Associates.

36. Rubin, R. S., Munz, D. C., \& Bommer, W. H. (2005). Leading from within: The effects of emotion recognition and personality on transformational leadership behavior. Academy of Management Journal, 48, 845-858.

37. Salovey, P., \& Mayer, J. D. (1990). Emotional intelligence. Imagination, Cognition, and Personality, 9 , 185-211.

38. Slaski, AM. \& Cartwright, S. (2002), "Health, performance and emotional intelligence: an exploratory study of retail managers", Stress and Health, Vol. 18, pp. 63-8.

39. Slaski, AM., \& Cartwright, S. (2003), "Emotional intelligence training and its implications for stress, health and performance", Stress and Health, in press.

40. Sosik, J. J., \& Megerian, L. E. (1999) Understanding leader emotional intelligence and performance. Group and Oraganization Management, 24 (3), 367-390.

41. Van Rooy, D. L., \& Viswesvaran, C. (2004). Emotional intelligence: A meta-analytic investigation of predictive validity and nomological net. Journal of Vocational Behavior, 65, 71-95.

42. Van Rooy, D. L., Viswesvaran, C., \& Pluta, P. (2005). A meta-analytic evaluation of construct validity: What is this thing called emotional intelligence? Human Performance, 18, 445-462. 